\title{
Pulsed Laser Deposited SnS-SnSe Nanocomposite as a New Anode Material for Lithium Ion Batteries
}

\author{
Kaiyuan Wei ${ }^{1,2}$, Yu Zhao ${ }^{1}$, Jiabin Liu $^{1}$, Shengzhou Liu ${ }^{3}$, Yixiu Cui ${ }^{1}$, Rongtao Zhu ${ }^{2}$, Yin Yang, ${ }^{3, *}$ \\ Yanhua Cuil,* \\ ${ }^{1}$ Institute of Electronic Engineering, China Academy of Engineering Physics, Mianyang 621000, P. R. \\ China \\ ${ }^{2}$ School of Chemical Engineering \& Technology, China University of Mining and Technology, \\ Xuzhou 221116, P. R. China \\ ${ }^{3}$ Institute of Advanced Synthesis, School of Chemistry and Molecular Engineering, Jiangsu National \\ Synergetic Innovation Center for Advanced Materials, Nanjing Tech University, Nanjing 211816, P. \\ R. China \\ *E-mail: ias_yyang@njtech.edu.cn (Y. Yang); cuiyanhua@netease.com (Y. Cui)
}

doi: $10.20964 / 2017.08 .62$

Received: 10 May 2017 / Accepted: 14 June 2017 / Published: 12 July 2017

\begin{abstract}
SnS-SnSe nanocomposite thin films are successfully fabricated by pulsed laser deposition (PLD) method and their electrochemical properties are investigated by cyclic voltammetry (CV) and discharge/charge measurements. SnS-SnSe composite electrode delivers an initial discharge capacity of $1225 \mathrm{mAh} / \mathrm{g}$, which is 1.8 and 2.6 times of $\mathrm{SnS}$ and $\mathrm{SnSe}$ thin film electrodes, respectively. The high capacity of composite electrode is speculated to be related to its large amounts of grain boundaries which can store more Li. Mechanistic study based on CV and ex situ X-ray diffraction (XRD) results imply that $\mathrm{SnS}-\mathrm{SnSe}$ composite decomposes to generate nanaosized $\mathrm{Li}_{\mathrm{x}} \mathrm{Sn}, \mathrm{Li}_{2} \mathrm{~S}$ and $\mathrm{Li}_{2} \mathrm{Se}$ during initial discharge process, which then form $\mathrm{Sn}_{2} \mathrm{SSe}$ single phase instead of composite phase upon charge process. The subsequent cycles are based on reversible electrochemical reaction between $\mathrm{Sn}_{2} \mathrm{SSe}$ phase and metallic Li.
\end{abstract}

Keywords: SnS-SnSe nanocomposite; Anode; Lithium ion batteries

\section{FULL TEXT}

(C) 2017 The Authors. Published by ESG (www.electrochemsci.org). This article is an open access article distributed under the terms and conditions of the Creative Commons Attribution license (http://creativecommons.org/licenses/by/4.0/). 